This article is licensed under the Creative Commons Attribution-NonCommercial 4.0 International License (CC BY-NC) (http://www.karger.com/Services/OpenAccessLicense). Usage and distribution for commercial purposes requires written permission.

\title{
Femtosecond Laser in situ Keratomileusis Flap Creation in Narrow Palpebral Fissure Eyes without Suction
}

\author{
John S.M. Chang Antony K.P. Law Jack C.M. Ng May S.Y. Cheng \\ Department of Ophthalmology, Hong Kong Sanatorium and Hospital, \\ Hong Kong, Hong Kong SAR
}

\section{Keywords}

Femtosecond - Laser in situ keratomileusis - Suction loss · Narrow palpebral fissure · Flap creation

\begin{abstract}
Purpose: To evaluate a surgical technique used in eyes with narrow palpebral fissure undergoing femtosecond laser flap creation without suction during laser in situ keratomileusis (LASIK). Methods: All data of 2 patient groups were collected through chart review. Group 1 consisted of 6 eyes with narrow palpebral fissure in which the suction ring was manually fixated and femtosecond laser was applied accordingly. Thirty comparison cases were randomly drawn from among eyes that underwent a standard LASIK procedure matched for age and preoperative refraction (group 2). Only 1 eye of each patient was selected to compare the refractive and visual outcomes between groups. Results: In all group 1 eyes, the flaps were created successfully with manual fixation of the suction ring without suction. No eyes lost 2 or more lines of vision. No significant difference was found in the safety and refractive outcomes between groups. Conclusion: Manual fixation of the suction ring in eyes with narrow palpebral fissure without suction was feasible for flap creation during LASIK.
\end{abstract}




\section{Case Reports in Ophthalmology}

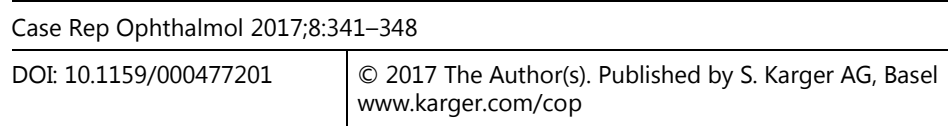

Chang et al.: Femtosecond Laser in situ Keratomileusis Flap Creation in Narrow Palpebral Fissure Eyes without Suction

\section{Introduction}

Laser in situ keratomileusis (LASIK) is a highly reliable and predictable procedure for treating refractive errors. Femtosecond laser is widely used in LASIK flap creation because it is able to produce flaps with highly consistent thickness [1] and has a lower intraoperative complication rate compared to procedures in which a microkeratome is used [2]. Complications commonly associated with microkeratome use, for example, incomplete flap, flap buttonholes, thin flap, and free cap, have significantly decreased after the use of the femtosecond laser for LASIK flap creation [2]. Although diffuse lamellar keratitis and femtosecond laser-specific LASIK complications, namely vertical gas breakthrough and suction loss, have been reported as disadvantages of femtosecond LASIK [3], the technological advancement in the femtosecond laser systems and accumulation of surgeons' experience have contributed to effective management of these complications.

Previous studies have suggested that suction loss during LASIK flap creation was more likely to occur in patients with flat corneas, small palpebral fissures, deep-set eyes, excessive eyelid squeezing, and movement by patient during surgery $[4,5]$. A common way to deal with the situations is to immediately reapply the suction [4]. If suction still could not be achieved, the procedure would be aborted and the surgery would be postponed $[5,6]$. In the current study, we described a technique that has been applied in our practice for femtosecond LASIK flap creation in eyes with narrow palpebral fissure in which suction could not be achieved. We also evaluated the safety of this technique. To the best of our knowledge, this technique has not been reported in the literature.

\section{Methods}

\section{Patients}

This retrospective study included patients who were scheduled for LASIK with the use of the Intralase iFS 150 Laser System (Abbott Medical Optics Inc., Santa Ana, CA, USA) for flap creation in the Hong Kong Sanatorium Hospital between January 2013 and September 2015. Patients with signs of keratoconus or severe dry eye were excluded from the study. We assigned patients to 1 of 2 groups according to the technique of LASIK flap creation. The patients in the "femtosecond LASIK with manual fixation of suction ring" group (group 1) had narrow palpebral fissures in which suction could not be achieved. The surgical technique was videotaped and recorded in the operation notes. The patients in the "standard femtosecond LASIK" group (group 2) had successful suction and the flap creation procedures were carried out as usual. The hospital research committee approved the study, which adhered to the tenets of the Declaration of Helsinki.

\section{Preoperative and Postoperative Examinations}

Preoperatively, all eyes underwent an ophthalmic examination that included measurements of horizontal and vertical palpebral fissures, ultrasound corneal pachymetry, corneal topography (Topolyzer Vario; Alcon Laboratories, Inc., Fort Worth, TX, USA), noncycloplegic subjective refraction, corrected distance visual acuity (CDVA), mesopic pupillary size (Topolyzer Vario; Alcon Laboratories, Inc.), slit-lamp biomicroscopy, and dilated fundus examina- 


\section{Case Reports in Ophthalmology}

\begin{tabular}{l|l}
\hline Case Rep Ophthalmol 2017;8:341-348 \\
\hline DOI: $10.1159 / 000477201$ & $\begin{array}{l}\text { ( ) 2017 The Author(s). Published by S. Karger AG, Basel } \\
\text { www.karger.com/cop }\end{array}$ \\
\hline
\end{tabular}

Chang et al.: Femtosecond Laser in situ Keratomileusis Flap Creation in Narrow Palpebral Fissure Eyes without Suction

tion. Three months postoperatively, the noncycloplegic subjective refraction, uncorrected distance visual acuity (UDVA), and CDVA were measured.

\section{Surgical Technique}

The same surgeon (J.S.M.C.) performed all surgeries. LASIK flaps were planned to be created using the Intralase iFS 150. For patients in group 1, it was difficult to insert the suction ring onto the corneal surface because of the narrow palpebral fissures. When placing the suction ring, the eyelashes and eyelids were trapped under the ring. Therefore, a cotton tip applicator was used to release the eyelashes and roll the upper eyelid upward to allow sufficient space for inserting the lip of the suction ring under the upper eyelid. The same procedure was performed to roll the lower lid downward while the suction ring was being pushed down. In all these cases, suction was applied but lost and a second attempt was performed. When this also failed, the eye was examined with the suction ring on the eye and the patient interface device (PID) docked. The surgeon maintained a constant pressure on the suction handle, and the patient was then instructed not to move her/his head and eyes. If no movement was detected and the PID fluid meniscus was outside the planned ablation area, the foot pedal was depressed and a femtosecond laser cut was attempted without suction. An important consideration was to ensure that there was not too much fluid in the eye, which might result in a too great distance between the PID and the eye and a resultant very thin or no femtosecond laser cut. In every instance, the flap was cut successfully, lifted, and an excimer laser (Wavelight EX500; Alcon Laboratories, Inc.) was applied (see online suppl. Clip 1, www.karger.com/doi/10.1159/000477201). The patients in group 2 underwent a standard femtosecond LASIK procedure similar to that described in the literature [4].

\section{Statistical Analysis}

All statistical analyses were performed using the SPSS software (Version 17, SPSS Inc., Chicago, IL, USA). All patients in group 1 were included for analysis. Thirty patients were selected from group 2 according to a list of computer-generated random numbers to match with each patient in group 1 for age and preoperative manifest refraction spherical equivalent (MRSE). One eye of each patient was selected randomly for analysis. For patients treated for monovision, only eyes with full correction were included. Continuous data were expressed in means and standard deviations. The UDVA and CDVA were converted into logarithm of the minimum angle of resolution (logMAR). The Mann-Whitney $U$ and Fisher exact tests were performed to compare the continuous and categorical parameters between groups, respectively. $p<0.05$ was considered statistically significant.

\section{Results}

A total of 1,499 patients were scheduled for femtosecond LASIK from January 2013 to September 2015. Suction could not be achieved in 6 patients (0.4\%; group 1) (4 women [66.7\%] and 2 men [33.3\%]). Thirty patients (22 women [73.3\%] and 8 men [26.7\%]) who underwent standard femtosecond LASIK (group 2) were selected for comparison.

Table 1 shows the demographics as well as preoperative and postoperative parameters of the groups. The age did not differ significantly between group 1 (mean, $36.8 \pm 13.2$ years) 


\section{Case Reports in Ophthalmology}

\begin{tabular}{l|l}
\hline Case Rep Ophthalmol 2017:8:341-348 \\
\hline DOI: 10.1159/000477201 & $\begin{array}{l}\text { ( ) } 2017 \text { The Author(s). Published by S. Karger AG, Basel } \\
\text { www.karger.com/cop }\end{array}$ \\
\hline
\end{tabular}

Chang et al.: Femtosecond Laser in situ Keratomileusis Flap Creation in Narrow Palpebral Fissure Eyes without Suction

and group 2 (mean, $32.3 \pm 9.1$ years) ( $p=0.418$ ). The vertical and horizontal palpebral fissures in group 1 (mean, $5.97 \pm 1.05 \mathrm{~mm}$ and $19.23 \pm 1.05 \mathrm{~mm}$, respectively) were significantly smaller than those in group 2 (mean, $8.70 \pm 1.29 \mathrm{~mm}$ and $27.37 \pm 1.97 \mathrm{~mm}$, respectively) ( $p<0.001$ for both comparisons). The target refraction was significantly less hyperopic in group 1 (mean, $0.42 \pm 0.49 \mathrm{dpt}$ ) than in group 2 (mean, $0.76 \pm 0.27 \mathrm{dpt})(p=0.033$ ). Other preoperative parameters including average keratometry, MRSE, and CDVA did not differ significantly between groups ( $p>0.05$ for all comparisons). The postoperative MRSE was significantly more hyperopic in group 2 (mean, $0.45 \pm 0.41 \mathrm{dpt}$ ) than in group 1 (mean, 0.02 $\pm 0.37 \mathrm{dpt}$ ). Other postoperative parameters including UDVA, CDVA, and error from the target refraction did not differ significantly between groups ( $p>0.05$ for all comparisons).

Table 2 shows the detailed demographics and preoperative and postoperative parameters of the 12 eyes of the 6 patients in group 1 . All eyes (100\%) had a postoperative CDVA of 20/20 or better, including 2 eyes (left eyes of patients 2 and 3) that were targeted for myopia which were not included in the main analysis. Two eyes $(16.7 \%)$ lost 1 line of CDVA from $20 / 15$ to 20/20; no eyes lost 2 lines or more. There was a similar percentage of eyes $(20 \%$, 12 eyes) losing 1 line of CDVA in group 2 ( $p=0.999$, Fisher exact test).

\section{Discussion}

The rate of suction loss during LASIK has rarely been reported in the literature. Tomita et al. [4] reported that the incidence of suction loss was $0.03 \%$ regardless of the specific cause. The incidence of insufficient suction of the microkeratome on the sclera was $0.99 \%$ in cases with a narrower palpebral fissure, younger age, and flatter keratometric readings [5]. The rate of suction loss specifically due to a narrow palpebral fissure, which has not been reported in the literature, was $0.4 \%$ in the current study. Since the current patients from Southern China are of shorter stature, the incidence should be higher than that in Caucasian patients. The current postoperative outcomes indicate that the procedure of manual fixation of the suction ring is possible. The postoperative MRSE was significantly more hyperopic in group 1 than in group 2, but that resulted from the difference in the target refraction. The target refraction was set to slightly hyperopic to compensate for future regression, which was reported to have an average annual rate of $0.15 \mathrm{dpt}$ [7] depending on the age and preoperative refraction. The deviation from the target refraction did not differ significantly between the groups. Overall, the postoperative refraction and visual outcomes were comparable to those of the standard LASIK procedure.

Published reports on suction loss during LASIK have only referred to cases with unsuccessful initial suction. Reattempting the suction was effective for continuing the surgery. The current cases in group 1 had very narrow palpebral fissures that did not provide sufficient space for a suction ring to have a firm grip on the conjunctiva. Reattempting the suction process for several times can result in conjunctival swelling. Switching the procedure to photorefractive keratectomy is an alternative [2], but the recovery is slower and there is a higher risk of developing haze [8], and mitomycin C may not be immediately available. Another option is to perform canthotomy to enlarge the palpebral fissure, which has been reported to be effective for patients with unsteady fixation undergoing microkeratome LASIK [5] and femtosecond laser-assisted cataract surgery in infants [9]. Most canthotomies heal well 


\section{Case Reports in Ophthalmology}

Case Rep Ophthalmol 2017;8:341-348

DOI: $10.1159 / 000477201$

(c) 2017 The Author(s). Published by S. Karger AG, Base www.karger.com/cop

Chang et al.: Femtosecond Laser in situ Keratomileusis Flap Creation in Narrow Palpebral Fissure Eyes without Suction

without scarring [10]. However, a potential problem with canthotomy is conjunctival edema, which requires application of topical coolants for hours; in severe cases, the surgery might have to be rescheduled to another day [5]. Manual fixation of the suction ring in the current study provided an easy and direct solution for flap creation without suction, thus avoiding the disadvantages associated with photorefractive keratectomy and canthotomy.

The current study showed that manual fixation of the suction ring for eyes without suction is possible in femtosecond LASIK, but this technique may not be appropriate for procedures, like femtosecond laser-assisted cataract surgery, that require highly precise measurements because the pressure from the surgeon's hand might alter the corneal thickness and the shape of the anterior chamber. During the time when microkeratomes were used routinely, the refractive procedure never proceeded in the absence of suction because of the possibilities of a free cap, small cap, or a short flap with a cut in the visual axis leading to scarring and visual loss. These will not occur with the femtosecond laser. If there is ocular movement during the laser shots, the surgeon can abandon the procedure; or if the patient moves his head excessively, the laser would simply be shot into the air. After the second suction attempt, there should be a suction impression on the conjunctiva which should make the eye a little more difficult to move. If the cut is unsuccessful, one can then try canthotomy and then repeat the cut with the same PID. Manual fixation of the suction ring during femtosecond LASIK is possible because it only involves flap creation. If there are small eye movements during the laser cut, the patient may have an uneven bed. The eye would just heal and a second attempt can be made a week later. This did not occur in any of the current cases.

Asano-Kato et al. [5] evaluated a few risk factors of insufficient fixation during LASIK. They found that insufficient fixation during LASIK occurred more likely in eyes with a flatter cornea. In their study, the mean keratometry was $42.40 \pm 1.37 \mathrm{dpt}$ in eyes with insufficient fixation, which was significantly lower than that in all patients $(43.60 \pm 1.40 \mathrm{dpt})$. AsanoKato et al. [5] also reported that younger age was another risk factor for suction loss. In their study, the mean age was $26.1 \pm 5.5$ years in eyes with insufficient fixation, which was significantly lower than that in all patients $(32.3 \pm 8.6$ years). The current patients with suction loss had a mean average keratometry of $44.46 \mathrm{dpt}$ and a mean age of 36.8 years, and the differences in average keratometry and age between groups were insignificant. We proposed that a narrow palpebral fissure was the primary reason for suction loss. In the current study, patients in group 1 had significantly narrower palpebral fissures than patients in group 2, which agrees with the findings by Asano-Kato et al. [5], where insufficient fixation occurred more likely in eyes with narrower palpebral fissure (mean, $9.6 \mathrm{~mm}$ ) compared to all eyes (mean, $11.0 \mathrm{~mm}$ ).

In conclusion, manual fixation of the suction ring is feasible in eyes in which suction cannot be achieved. Manual fixation prevents surgical delay and the postoperative outcomes were not inferior to standard LASIK flap creation procedure.

\section{Acknowledgments}

Dr. Chang has received travel expenses from Abbott Medical Optics, Inc. and Avedro, Inc., and lecture honorarium from Alcon Laboratories, Inc. 
Statement of Ethics

The hospital research committee approved the study, which adhered to the tenets of the Declaration of Helsinki.

\section{Disclosure Statement}

No authors have financial interests in any aspect of this report. No conflicting relationship exists for all authors.

\section{References}

1 Chen S, Feng Y, Stojanovic A, Jankov MR II, Wang Q: IntraLase femtosecond laser vs mechanical microkeratomes in LASIK for myopia: a systematic review and meta-analysis. J Refract Surg 2012;28:15-24.

2 Moshirfar M, Gardiner JP, Schliesser JA, et al: Laser in situ keratomileusis flap complications using mechanical microkeratome versus femtosecond laser: retrospective comparison. J Cataract Refract Surg 2010;36:1925-1933.

3 Chang JSM: Complications of sub-bowman's keratomileusis with a femtosecond laser in 3,009 eyes. J Refract Surg 2008;24:S97-S101.

-4 Tomita M, Watabe M, Nakamura T, Nakamura N, Tsuru T, Waring GO: Management and outcomes of suction loss during LASIK flap creation with a femtosecond laser. J Refract Surg 2012;28:32-36.

5 Asano-Kato N, Toda I, Hori-Komai Y, Takano Y, Tsubota K: Risk factors for insufficient fixation of microkeratome during laser in situ keratomileusis. J Refract Surg 2002;18:47-50.

6 Weisenthal RW, Salz J, Sugar A, et al: Photorefractive keratectomy for treatment of flap complications in laser in situ keratomileusis. Cornea 2003;22:399-404.

7 Alio JL, Soria F, Abbouda A, Pena-Garcia P: Laser in situ keratomileusis for -6.00 to -18.00 diopters of myopia and up to -5.00 diopters of astigmatism: 15-year follow-up. J Cataract Refract Surg 2015;41:33-40.

-8 Shortt AJ, Allan BDS, Evans JR: Laser-assisted in-situ keratomileusis (LASIK) versus photorefractive keratectomy (PRK) for myopia. Cochrane Database Sys Rev 2013;1:005135.

-9 Dick HB, Schultz T: Femtosecond laser-assisted cataract surgery in infants. J Cataract Refract Surg 2013;39:665-668.

10 Knoop K, Trott A: Ophthalmologic procedures in the emergency department - part I: Immediate sightsaving procedures. Acad Emerg Med 1994;1:408-412. 
Chang et al.: Femtosecond Laser in situ Keratomileusis Flap Creation in Narrow Palpebral Fissure Eyes without Suction

Table 1. Comparison of demographics as well as preoperative and postoperative parameters between patients in group 1 (femtosecond laser in situ keratomileusis with manual fixation of suction ring) and group 2 (standard laser in situ keratomileusis procedure)

\begin{tabular}{|c|c|c|c|c|c|c|}
\hline \multirow[t]{2}{*}{ Parameters } & \multicolumn{2}{|c|}{ Group $1(n=6)$} & \multicolumn{2}{|c|}{ Group $2(n=30)$} & \multirow[t]{2}{*}{$z$} & \multirow[t]{2}{*}{$p$ value } \\
\hline & mean $\pm S D$ & median (min, max) & mean $\pm S D$ & median (min, max) & & \\
\hline \multicolumn{7}{|l|}{ Preoperative } \\
\hline Female, $n(\%)$ & $4(66.7)$ & & $22(73.3)$ & & - & $0.999 \mathrm{a}$ \\
\hline Age, years & $36.8 \pm 13.2$ & $38.0(19,56)$ & $32.3 \pm 9.1$ & $29.5(19,56)$ & -0.83 & 0.418 \\
\hline Vertical palpebral fissure, $\mathrm{mm}$ & $5.97 \pm 1.05$ & $5.95(4.8,7.6)$ & $8.70 \pm 1.29$ & $9.00(6.0,11.0)$ & -3.42 & $<0.001^{*}$ \\
\hline Horizontal palpebral fissure, $\mathrm{mm}$ & $19.23 \pm 2.53$ & $18.5(16.0,23.5)$ & $27.37 \pm 1.97$ & $28.00(22.0,31.0)$ & -3.83 & $<0.001 *$ \\
\hline Pupillary size, mm & $6.50 \pm 0.50$ & $6.50(6.0,7.0)$ & $6.76 \pm 0.86$ & $7.00(4.5,8.0)$ & -0.79 & 0.457 \\
\hline Average keratometry, dpt & $44.46 \pm 0.78$ & $44.69(43.25,45.19)$ & $44.15 \pm 1.13$ & $43.94(42.38,46.25)$ & -0.76 & 0.467 \\
\hline Target refraction, dpt & $0.42 \pm 0.49$ & $0.38(-0.30,1.30)$ & $0.76 \pm 0.27$ & $0.75(0.30,1.50)$ & -2.19 & $0.033^{*}$ \\
\hline MRSE, dpt & $-4.19 \pm 4.28$ & $-3.81(-10.88,2.25)$ & $-5.10 \pm 2.44$ & $-4.56(-12.75,-1.88)$ & -0.70 & 0.493 \\
\hline CDVA, $\log M A R$ & $-0.06 \pm 0.07$ & $-0.06(-0.12,0.00)$ & $-0.04 \pm 0.07$ & $0.00(-0.12,0.00)$ & -0.66 & 0.576 \\
\hline \multicolumn{7}{|l|}{ Postoperative } \\
\hline MRSE, dpt & $0.02 \pm 0.37$ & $0.00(-0.50,0.50)$ & $0.45 \pm 0.41$ & $0.44(-0.25,1.25)$ & -2.09 & $0.037^{*}$ \\
\hline Error from the target refraction, dpt & $-0.40 \pm 0.62$ & $-0.25(-1.25,0.25)$ & $-0.31 \pm 0.35$ & $-0.31(-1.00,0.50)$ & -0.04 & 0.984 \\
\hline UDVA, logMAR & $-0.05 \pm 0.09$ & $-0.06(-0.12,0.10)$ & $-0.06 \pm 0.06$ & $0.00(-0.12,0.00)$ & -0.17 & 0.881 \\
\hline CDVA, logMAR & $-0.08 \pm 0.06$ & $-0.12(-0.12,0.00)$ & $-0.07 \pm 0.06$ & $-0.12(-0.12,0.00)$ & -0.45 & 0.725 \\
\hline
\end{tabular}

CDVA, corrected distance visual acuity; logMAR, logarithm of the minimum angle of resolution; MRSE, manifest refraction spherical equivalent; UDVA, uncorrected distance visual acuity. $z$, Mann-Whitney U test. a Fisher exact test. * Significant at $p=0.05$. 
Chang et al.: Femtosecond Laser in situ Keratomileusis Flap Creation in Narrow Palpebral Fissure Eyes without Suction

Table 2. Demographics as well as preoperative and postoperative parameters of patients in group 1 (femtosecond laser in situ keratomileusis with manual fixation of suction ring)

\begin{tabular}{|c|c|c|c|c|c|c|c|c|c|c|c|c|}
\hline \multirow{2}{*}{$\begin{array}{l}\text { Case/ } \\
\text { eye }\end{array}$} & \multirow{2}{*}{$\begin{array}{l}\text { Gen- } \\
\text { der }\end{array}$} & \multirow{2}{*}{$\begin{array}{l}\text { Age, } \\
\text { years }\end{array}$} & \multicolumn{6}{|c|}{ Preoperative } & \multicolumn{4}{|c|}{ Postoperative } \\
\hline & & & $\begin{array}{l}\text { MRSE, } \\
\text { dpt }\end{array}$ & $\begin{array}{l}\text { target } \\
\text { refraction, } \\
\text { dpt }\end{array}$ & CDVA & $\begin{array}{l}\text { average } \\
\text { keratometry, } \\
\text { dpt }\end{array}$ & $\begin{array}{l}\text { vertical } \\
\text { palpebral } \\
\text { fissure, } \mathrm{mm}\end{array}$ & $\begin{array}{l}\text { horizontal } \\
\text { palpebral } \\
\text { fissure, } \mathrm{mm}\end{array}$ & $\begin{array}{l}\text { MRSE, } \\
\mathrm{dpt}\end{array}$ & $\begin{array}{l}\text { error from } \\
\text { the target } \\
\text { refraction, } \\
\text { dpt }\end{array}$ & UDVA & CDVA \\
\hline $1 / \mathrm{R}$ & $\mathrm{F}$ & 35 & -4.13 & 0.50 & $20 / 15$ & 43.90 & 7.4 & 23.0 & 0.63 & 0.13 & $20 / 25$ & $20 / 20$ \\
\hline 1/L & $\mathrm{F}$ & 35 & -4.00 & 0.25 & $20 / 20$ & 43.80 & 7.6 & 23.5 & 0.38 & 0.13 & $20 / 20$ & $20 / 20$ \\
\hline $2 / \mathrm{R}$ & $\mathrm{F}$ & 56 & 2.25 & -0.25 & $20 / 20$ & 44.90 & 6.5 & 16.0 & 0.00 & 0.25 & $20 / 20$ & $20 / 20$ \\
\hline $2 / \mathrm{L}$ & $\mathrm{F}$ & 56 & 2.00 & -2.25 & $20 / 20$ & 44.60 & 6.0 & 15.6 & -2.50 & -0.25 & $20 / 70$ & $20 / 15$ \\
\hline $3 / \mathrm{R}$ & $\mathrm{F}$ & 44 & -6.00 & 0.50 & $20 / 15$ & 45.10 & 5.6 & 18.4 & -0.50 & -1.00 & $20 / 25$ & $20 / 15$ \\
\hline $3 / \mathrm{L}$ & $\mathrm{F}$ & 44 & -5.00 & -1.00 & $20 / 15$ & 45.00 & 6.0 & 18.0 & -1.50 & -0.5 & $20 / 80$ & $20 / 15$ \\
\hline $4 / \mathrm{R}$ & M & 19 & -3.63 & 0.50 & $20 / 15$ & 43.30 & 4.6 & 19.0 & 0.25 & -0.25 & $20 / 15$ & $20 / 15$ \\
\hline $4 / \mathrm{L}$ & M & 19 & -2.88 & 0.50 & $20 / 15$ & 44.50 & 4.8 & 18.5 & 0.50 & 0.00 & $20 / 15$ & $20 / 15$ \\
\hline $5 / \mathrm{R}$ & M & 26 & -10.88 & 1.25 & $20 / 20$ & 43.30 & 5.0 & 18.5 & 0.00 & -1.25 & $20 / 15$ & $20 / 15$ \\
\hline $5 / \mathrm{L}$ & M & 26 & -10.88 & 1.25 & $20 / 15$ & 43.50 & 5.5 & 19.0 & 0.00 & -1.25 & $20 / 15$ & $20 / 15$ \\
\hline $6 / \mathrm{R}$ & $\mathrm{F}$ & 41 & -3.63 & 0.25 & $20 / 15$ & 45.20 & 6.3 & 20.5 & -0.25 & -0.50 & $20 / 15$ & $20 / 15$ \\
\hline $6 / L$ & $\mathrm{~F}$ & 41 & -3.63 & 0.50 & $20 / 15$ & 45.10 & 6.6 & 20.0 & 0.00 & -0.50 & $20 / 20$ & $20 / 20$ \\
\hline
\end{tabular}

$\mathrm{R}$, right eye; L, left eye; MRSE, manifest refraction spherical equivalent; CDVA, corrected distance visual acuity; K, keratometry; UDVA, uncorrected distance visual acuity. 